EPiC Series in Engineering
Volume 3, 2018, Pages 1804-1813
HIC 2018. 13th International
Conference on Hydroinformatics

\title{
Modelling green roof detention performance in cold climates
}

\author{
Ingrid L. Russwurm ${ }^{1}$, Birgitte G. Johannessen ${ }^{1}$, Ashenafi Gragne ${ }^{1}$, Jardar \\ Lohne $^{1}$, Tone M. Muthanna ${ }^{1}$ \\ 1 Department of Civil and Environmental Engineering, Norwegian University of Science and \\ Technology NTNU, S. P. Andersens veg 5, Trondheim 7491, Norway
}

\begin{abstract}
Green roofs (GRs) have become a popular sustainable drainage system (SuDS) technology in urban areas. As many countries and regions experience political encouragement and substitution schemes in implementing GRs, there is a need for reliant models that can support designing purposes. The stormwater management model's (SWMM) Low Impact Development Green Roof (LID-GR) control is used to simulate the hydrological detention performance of two GRs, GR1 and GR2, with different drainage properties located in Oslo, Norway. This study uses event-based data to replicate GR runoff. Accordingly, four event-models were calibrated using the Shuffled Complex Evolution algorithm with the Nash-Sutcliffe criteria (NSE) as the objective function. Eight events were used for model validation. Simulation results revealed that SWMM's LID module can capture response of the GRs even though the adequacy varies among events. During calibration two GR1 (0.55 and 0.72) and three GR2 $(0.73,0.88$ and 0.51$)$ event-models yielded NSE $>0.5$. However, only parameter sets of two GR2 event-models yielded NSE $>0.5$ when applied to the validation events. Parameter sensitivity analysis exhibited significant correlation between conductivity slope and maximum precipitation intensity. The study shows potential of SWMM as a design tool if supplemented with a calibration algorithm and some adjustments to the LID module.
\end{abstract}

\section{Introduction}

Green roofs (GRs) have the potential to solve more than one engineering problem. Besides mitigating stormwater runoff, green roofs supply aesthetic values, enhanced ecologic habitat and reduced cooling/heating needs in buildings. Green roofs allow for a natural water balance in urban areas and lessen urban heat island effect. The extent to which roofs occupy space (40-50\% of the impermeable surface) in urban areas render green roof performance particularly interesting for addressing stormwater management challenges. Their behaviour, however, is not adequately understood from a hydrologic perspective. In particular, this concerns predicting their detention capacities. 
Considering the complexity of GR performance, the traditional hydrologic design criteria (rainfall events with different intensities, durations and frequencies) do not prove sufficient. GR retention and detention processes are site specific and factors such as climatic conditions (Johannessen et al., 2017), seasonal variations (Voyde et al., 2010) and rainfall characteristics (Hakimdavar et al., 2014) influence their performance. Considering this, stormwater engineers and local municipalities need reliable and precise methods for quantifying green roof performance in advance of construction (Carson et al., 2017).

Physical modelling based on site-specific characteristics is one manner by which the performance can be predicted before construction. Such modelling depends to a significant degree on the quality of the models used.

SWMM is a frequently used model for predicting runoff from subcatchments. After the upgrade in 2015, LID control modules were included, rendering it possible to model SuDS controls, such as GRs (LID-GR), bioretention cells and permeable surfaces.

This study aims to answer the following research questions:

- How accurately can SWMMs LID-GR module predict the detention performance of two extensive GRs with different drainage properties?

- How does model input in form of precipitation characteristics and initial conditions affect the model parameters?

The theoretical framework of the study is found in section 2. Section 3 specifies the methodology to assess the research questions. The results of the study are presented and discussed in section 4 and 5 respectively. Lastly, conclusions are drawn and proposals on further research are given.

\section{Theoretical framework}

Today we experience an increased interest of GRs in many regions and countries (Berndtsson, 2010; Johannessen et al., 2017), including Nordic countries such as Norway where runoff mitigation has been actualized in several municipalities, e.g. the municipality of Oslo. Oslo is experiencing that the combined sewage system is under pressure in many areas, stimulating to find new technologies to improve runoff mitigation. GRs are considered as a measure to account for population growth and climatic challenges.

A system's response to locally derived design storms in form of quantity of water the system can detain is widely considered when designing SuDSs. These processes differ from continuous retention processes, where the GR's behaviour between storms are important. GR detention performance is dependent on initial conditions affecting moisture content in the different GR layers upon precipitation events (Carson et al., 2013; Stovin et al., 2012; Voyde et al., 2010). These conditions are decided by a GRs retention performance, i.e. the GRs ability to remove stormwater through evapotranspiration and storage, implying that detention mechanisms cannot be fully understood without considering retention processes. However, separating the two processes and assessing consistent performance terms allow for improved consistency when addressing specific objectives for GRs (Stovin et al., 2017).

In literature, several approaches for modelling detention performance have been presented. Examples are simple reservoir routing methods (Kasmin et al., 2010; Villarreal et al., 2005), commercial groundwater models such as HYDRUS 1-D (Hakimdavar et al., 2014; Hilten et al., 2008), MIKE URBAN (Locatelli et al., 2014) and SWMM (Burszta-Adamiak et al., 2013; Krebs et al., 2016; Palla et al., 2015), among others. SWMM is a dynamic precipitation-runoff model used to simulate runoff quality and quantity mainly in urban subcatchments but has also been used to simulate runoff from GRs. This has mainly been done through the GR module, (Carson et al., 2013; Cipolla et al., 2016; Palla \& Gnecco, 2015; Peng et al., 2017), but the BRC-module has also been applied (Cipolla et al., 2016). The LID-GR module is expressed by a surface layer, substrate layer and a drainage layer. All layers are 
defined by a set of parameters. The surface layer parameters are shown to have little effect on detention processes as there is normally no ponding on the surface of a GR (Peng \& Stovin, 2017) and because of the high permeability found in GR soils (Krebs et al., 2016). This implies that the substrate and drainage layers are most important when modelling detention routines.

\section{Methods}

\subsection{GR test site in Oslo, Norway}

The GR test site is a $24 \mathrm{~m} 2$ garage roof with a slope of $5.5 \%$ in Oslo and has been operating since 2009. A residence south of the site and the roof's north-faced orientation makes it exposed to shade. These factors, including the site's high elevation (215 m.a.s.1.), makes the test site "a worst-case scenario" (Braskerud, 2014). The site consists of two vegetated roofs, GR1 and GR2, and a reference roof, RR. Each plot with $2 \mathrm{~m}$ width and $4 \mathrm{~m}$ length. GR1 is built up of a $25 \mathrm{~mm}$ Nophadain $5+1$ drainage board under a $30 \mathrm{~mm}$ ready-made moss-sedum vegetation mat. The drainage board has a water holding capacity of $5.81 / \mathrm{m} 2$. On the 8th of August 2011, a VT-filt of $10 \mathrm{~mm}$ was added between the drainage board and substrate layer to improve the water holding capacity. GR2 is constructed of a $10 \mathrm{~mm}$ VTfilt under a $30 \mathrm{~mm}$ moss-sedum mat. The roofs are in other words identical, except from the plastic board on GR1. A laboratory analysis measured an average water holding capacity of 7-10 $\mathrm{mm}$ for the VT-filt. Soil moisture content was recorded every $15 \mathrm{~min}$ in both GRs using Vegetronix sensors. The sensors were installed and calibrated in august 2010 (Braskerud, 2014). Runoff from GR1, GR2 and RR flows through separate gutters into a 2201 isolated oil barrels. Water level is measured by a pressure sensor. The barrels are emptied when the water level reaches $80 \mathrm{~cm}$. To account for missing data points, the barrels has been emptied manually during dry periods. In cases where runoff is generated, missing data points are filled by interpolation. Precipitation is monitored by a heated Lambrecht 1518 H3 rain gauge with a recording interval of $1 \mathrm{~min}$ and $0.1 \mathrm{~mm}$ resolution (after 2009). For more detailed description of the test beds, see Braskerud (2014).

\subsection{Modelling GR detention performance}

The roofs were modelled by applying an LID-GR module to two subcatchments, S1 and S2, each being $100 \%$ occupied by their respective LID-GR control. Two outlets were added and connected to the LID-module. The model analysis started one hour before reporting time to assure model burn-in.

Earlier studies define events as the antecedent dry period is at least 6 hours (Stovin et al., 2012; Voyde et al., 2010), among others. To easily compare GR performance, this definition is also used in this study. Consequently, a total of 680 events were identified from August 2009 to June 2016. Events before august 2010 were excluded as soil moisture measurements were missing before this. Events with more than one contributing rainfall and events with durations larger than 24 hours were removed, resulting in 160 remaining events. Events with high maximum intensity were chosen for calibration and validation purposes. Event descriptions are found in Table 1.

All initial parameters required by SWMM LID-GR and sources for parameter estimation are listed in Table 2. They were either obtained by literature, laboratory analysis, set as default as proposed by SWMM, or set according to the physical properties of the GRs. The climatologic parameter $C_{P E T}$ defined as the potential evaporation coefficient was set to zero as evapotranspiration is not considered in this event-based study.

Berm height is set to $3 \mathrm{~mm}$ to avoid system overflow. As GR substrate media is very porous, water ponding on the surface is assumed not to occur. Furthermore, the drainage mat in SWMM's LID-GR module only accounts for water transportation and no storage. To represent the storage capacity in the 
filt mat of both roofs and the plastic board of GR1, extra thickness was added in the substrate layer of both roofs, see $*$ in Table 2 .

\begin{tabular}{|c|c|c|c|c|c|c|c|c|}
\hline $\begin{array}{c}\text { Event } \\
\quad \#\end{array}$ & $\begin{array}{c}\text { Start time } \\
\text { (dd/mm/yy } \\
\text { HH:MM) }\end{array}$ & $\begin{array}{c}\text { Duratio } \\
\mathrm{n}(\mathrm{h})\end{array}$ & $\begin{array}{l}\text { Total } \\
\text { prec. } \\
(\mathrm{mm})\end{array}$ & $\begin{array}{l}\text { Maximu } \\
\mathrm{m} \\
\text { intensity } \\
(\mathrm{mm} / \mathrm{h})\end{array}$ & $\begin{array}{l}\text { Return } \\
\text { period }\end{array}$ & $\begin{array}{c}\text { GR1/ } \\
\text { GR2 } \\
\text { initia } \\
1 \\
\text { moist } \\
+\end{array}$ & $\begin{array}{l}\text { GR1 } \\
\text { runoff } \\
(\mathrm{mm})\end{array}$ & $\begin{array}{c}\text { GR2 } \\
\text { runoff } \\
(\mathrm{mm})\end{array}$ \\
\hline $1^{\mathrm{C}}$ & 07.06.11 07:09 & 2.75 & 29.5 & 1.22 & 5 & $\mathrm{D} / \mathrm{D}$ & 19.2 & 15.4 \\
\hline 2 & 19.07.11 02:26 & 6.02 & 17.4 & 0.54 & $<2$ & $\mathrm{~W} / \mathrm{W}$ & 13.4 & 13.5 \\
\hline 3 & 01.07.12 07:59 & 9.37 & 11.8 & 0.86 & $<2$ & $\mathrm{~W} / \mathrm{M}$ & 9.9 & 9.4 \\
\hline 4 & $17.09 .1203: 03$ & 4.82 & 9.9 & 0.47 & $<2$ & $\mathrm{~W} / \mathrm{W}$ & 6.8 & 6.7 \\
\hline $5^{\mathrm{C}}$ & $04.08 .1317: 24$ & 0.80 & 9.0 & 0.53 & $<2$ & $\mathrm{M} / \mathrm{M}$ & 4.0 & 4.1 \\
\hline 6 & $12.08 .1311: 34$ & 2.45 & 14.0 & 0.62 & $<2$ & $\mathrm{M} / \mathrm{M}$ & 7.3 & 6.3 \\
\hline 7 & $07.07 .1410: 47$ & 3.80 & 17.6 & 0.91 & $<2$ & $\mathrm{M} / \mathrm{M}$ & 5.6 & 5.6 \\
\hline 8 & $25.08 .1411: 06$ & 5.60 & 10.2 & 1.07 & $<2$ & $\mathrm{~W} / \mathrm{W}$ & 7.9 & 7.4 \\
\hline 9 & $02.08 .1500: 37$ & 4.40 & 12.6 & 0.63 & $<2$ & $\mathrm{M} / \mathrm{D}$ & 6.1 & 6.5 \\
\hline $10^{\mathrm{C}}$ & $28.08 .1121: 05$ & 20.50 & 56.4 & 0.43 & 20 & $\mathrm{~W} / \mathrm{W}$ & 50.5 & 47.8 \\
\hline $11^{\mathrm{C}}$ & $26.06 .1415: 47$ & 14.35 & 45.0 & 2.06 & 5 & $\mathrm{D} / \mathrm{D}$ & 23.8 & 26.4 \\
\hline 12 & 03.08.14 19:49 & 22.05 & 40.4 & 0.97 & 2 & $\mathrm{M} / \mathrm{M}$ & 21.1 & 22.0 \\
\hline
\end{tabular}

Table 1: Events chosen for calibration and validation. $C$ denotes calibration set. The calibration events vary in intensity, duration, return period and initial moisture content.

\subsection{Evaluating model performance}

Uncalibrated runoff from the 4 chosen calibration events was simulated for both GRs, using initial values found in Table 2. Performance was evaluated through the Nash-Sutcliffe Efficiency index (NSE) and peak flow time error (PFE), calculated as the time difference in minutes between observed and simulated time to peak. This study defines model performance as sufficient when NSE $\geq 0.5$.

Model calibration aimed at finding the optimal parameter set that simulates runoff flow rates as similar as possible to the observed ones. Optimal parameter search was accomplished by applying the Shuffle Complex Evolution algorithm (Duan et al., 1992). The Nash-Sutcliffe criteria was used as the objective function in the calibration exercise.

Eight events were applied to validate the model. Model performance was assessed through NSE and PFE. As time delay is of concern when designing SuDSs, model accuracy assessment should be based on criteria concerning time as well as volume. The four optimal parameter sets found in the calibration procedure were applied for model validation of the eight validation events.

Parameter variations and sensitivity are investigated with respect to model inputs. To obtain an adequate number of samples, GR2 is calibrated for all events, to find their respective optimal parameter set. Relations between parameter values, rainfall characteristics and initial conditions are examined. 


\begin{tabular}{|c|c|c|c|}
\hline \multirow[b]{2}{*}{ Parameter } & \multicolumn{2}{|c|}{ GR1/GR2 } & \multirow[b]{2}{*}{ Source } \\
\hline & $\begin{array}{l}\text { Initial } \\
\text { value }\end{array}$ & Range & \\
\hline \multicolumn{4}{|l|}{ LID SURFACE } \\
\hline Berm height (mm) & 3 & - & Assumed \\
\hline Vegetation volume $(0-1)$ & 0.1 & - & Default \\
\hline $\begin{array}{ll}\text { Surface } & \text { roughness } \\
\text { (Manning's n) } & \end{array}$ & 0.2 & - & (Cipolla et al., 2016) \\
\hline \multicolumn{4}{|l|}{ LID SOIL } \\
\hline Thickness (mm) & $(40) / 65^{*}$ & - & Manufactural \\
\hline PorosityC (0-1) & 0.65 & $\begin{array}{c}0.55- \\
0.75\end{array}$ & Laboratory analysis \\
\hline Field capacityC (0-1) & 0.45 & $\begin{array}{c}0.35- \\
0.55\end{array}$ & $\begin{array}{l}\text { Laboratory analysis (Bengtsson, } \\
2005 \text { ) }\end{array}$ \\
\hline Wilting point $(0-1)$ & 0.1 & - & Assumed \\
\hline ConductivityC $(\mathrm{mm} / \mathrm{h})$ & (80) 1000 & $36-4200$ & (Rossman, 2015) \\
\hline Conductivity slopeC & $(50) / 40$ & $5-60$ & $\begin{array}{l}\text { (Cipolla et al., 2016; Peng \& } \\
\text { Stovin, 2017) }\end{array}$ \\
\hline Suction head (mm) & (110) 60 & - & $\begin{array}{l}\text { (Krebs et al., 2016; Peng \& Stovin, } \\
\text { 2017) }\end{array}$ \\
\hline \multicolumn{4}{|l|}{ LID-GR DRAIN } \\
\hline Thickness (mm) & 10 & - & Manufactural \\
\hline Void fractionC (0-1) & 0.72 & $0.01-1$ & Manufactural \\
\hline $\begin{array}{ll}\text { Surface } & \text { roughnessC } \\
\text { (Manning's n) } & \\
\end{array}$ & 0.2 & $0.02-0.4$ & $\begin{array}{l}\text { (Peng \& Stovin, 2017; Rossman, } \\
\text { 2015) }\end{array}$ \\
\hline
\end{tabular}

Table 2: Parameters required by SWMM GR and BRC-LID modules. The exponent ${ }^{\mathrm{C}}$ denotes parameters subject to calibration. Parenthesis represent values applied in GR1. * denotes extra storage capacity in the drainage layers of the GRs, which are represented in the substrate.

\section{Results}

\subsection{Uncalibrated and calibrated model performance}

For GR2, two events, $1^{\mathrm{C}}$ and $10^{\mathrm{C}}$, result in satisfactory model performance for the uncalibrated model, with NSE $=0.55$ and 0.72 respectively (Table 3 ). Time to peak has a good fit for both events $\left(\mathrm{PFE}=1\right.$ and $<0$ for event $1^{\mathrm{C}}$ and $\left.10^{\mathrm{C}}\right)$. Uncalibrated simulations form the latter calibration events are poor, with NSE $<0$ (event $5^{\mathrm{C}}$ and event $11^{\mathrm{C}}$ ). Considering GR1, the uncalibrated model is not sufficient, with NSE ranging from -2.4 (event $5^{\mathrm{C}}$ ) to 0.43 (event $10^{\mathrm{C}}$ ). Peak flow is overestimated in all simulations.

In general, simulation results from the calibrated SWMM LID-module of GR2 have satisfactory performance, except event $5^{\mathrm{C}}$. For all calibrated events, NSE is raised from uncalibrated results (Table 3). This also applies for GR1, although NSEs are lower. Calibration results from GR1 are good for event $1^{\mathrm{C}}$ and $10^{\mathrm{C}}$, but poor for the two others.

\subsection{Model validation}

GR1 shows unsatisfactory calibration results and poor fits for the validation procedure. Considering GR2, however, parameter values transferred from events $5^{\mathrm{C}}$ and $10^{\mathrm{C}}$ result in acceptable model performance with an NSE $>0.55$ for all validation events, except for the significant event 11 (return 
period 5 years) and event 3 using the parameter set from event $10^{\mathrm{C}}$ (Table 4 ). Even though event $5^{\mathrm{C}}$ is poorly calibrated for both GRs, it is noteworthy that its parameter set gives the most satisfactory simulations for the validation events. Figure 2 shows validation runs performed on GR2 using the parameter set derived from event $5^{\mathrm{C}}$.

\begin{tabular}{ccc|cc}
\hline & \multicolumn{2}{c|}{ GR1 } & \multicolumn{2}{c}{ GR2 } \\
Event \# & NSE pre cal & NSE after cal & NSE pre cal & NSE after cal \\
\hline 1 & $<0$ & $\mathbf{0 . 6 2}$ & $\mathbf{0 . 5 5}$ & $\mathbf{0 . 7 3}$ \\
5 & $<0$ & $<0$ & $<0$ & 0.33 \\
10 & 0.43 & $\mathbf{0 . 7 2}$ & $\mathbf{0 . 7 2}$ & $\mathbf{0 . 8 8}$ \\
11 & 0.17 & $<0$ & 0.40 & $\mathbf{0 . 5 1}$ \\
\hline
\end{tabular}

Table 3: NSE values before and after calibration. Bold text denotes satisfactory model performance.

In the case of GR1, calibration results from this event are the only results able to provide adequate model performance, despite delayed time to peak for all validation events. Event $5^{\mathrm{C}}$ has low duration $(0.8 \mathrm{~h})$, lower rainfall volume $(9 \mathrm{~mm})$ and a lower maximum intensity $(0.53 \mathrm{~mm} / \mathrm{h})$ than other calibration events. The successful transfer of event $5^{\mathrm{C}}$ 's parameter set might be explained by a considerable number of events having similar rainfall characteristics as this event.

In view of GR2, event 2 is best fitted by the set derived from event $10^{\mathrm{C}}$. These events have large return periods ( 5 and 20 years, respectively) and complex hydrographs. The parameter set from event $11^{\mathrm{C}}$ fail in the validation procedure, assumingly due to the sudden high intensity precipitation.

The model fails to simulate the storage capacity causing peak flow overestimation and delay of time to peak compared to observed ones. Some events appear easy to reproduce, such as event 4,8 and 9 (see NSE, Table 4). These events have in common that they have lower precipitation depths, no distinct peaks (except event 8 ) and long durations. Additionally, maximum intensity occurs moderately late for these events.

Peak flows are in general simulated lagging the observed ones (Figure 2). No runoff is simulated for most of validation events derived from event $11^{\mathrm{C}}$, resulting in no PFE calculations.

Event 7 generates very little observed runoff from both GRs and the neighboring black roof $(8 \mathrm{~mm})$, which gives reasons to assume measuring error in the precipitation gauge for this day.

\subsection{Model parameter sensitivity}

To investigate parameter sensitivity to model input, all events were calibrated to ensure a large variability concerning rainfall characteristics and roof initial conditions. Simulations are only applied to GR2 and all parameter sets obtained by calibration iterations with NSE $>0.5$ were analyzed. Event $5^{\mathrm{C}}$, event 7 (see section 4.3) and event 12 were unable to receive NSE $>0.5$ and are therefore not part of the analysis. Correlations between model parameters and rainfall characteristics together with initial conditions of the roof were examined.

Conductivity slope (conds) and Manning's $\mathrm{n}$ in the drainage layer (n) were found to be correlated with maximum intensity. A minor correlation between Manning's $\mathrm{n}$ and precipitation volume was also found $(\mathrm{R} 2=0.50)$. Conductivity slope increases as the maximum intensity of an event increases. For events 6, 8 and 9, the void fraction is calibrated to be high, while Manning's $\mathrm{n}$ is low. A larger void fraction will decrease the contribution of the roughness, implying nearly free water passage through this layer. Conductivity values are relatively low for these events, suggesting that the substrate parameters determine the flow rate, and that detention processes in these cases occur in the module's substrate layer. For initial saturation, no clear correlations with the optimal parameters were observed. Porosity $(p)$ and field capacity $(f c)$ are calibrated to have realistic values and are similar for all calibration assessments with a mean of $70 \% \pm 4 \%$ and $30 \% \pm 8 \%$, respectively. The parameters' stability implies the module succeeds at modelling these parameters. 


\begin{tabular}{ccc|cc|cc|cc}
\hline \multirow{2}{*}{$\begin{array}{c}\text { Validation } \\
\text { events }\end{array}$} & \multicolumn{2}{c}{$1^{\mathrm{C}}$} & \multicolumn{2}{|c|}{ Calibration events } & \multicolumn{2}{c}{$15^{\mathrm{C}}$} & \multicolumn{2}{c}{$11^{\mathrm{C}}$} \\
& NSE & PFE & NSE & PFE & NSE & PFE & NSE & PFE \\
\hline 2 & 0.29 & -7 & $(0.27) \mathbf{0 . 5 1}$ & $(-7) \mathbf{2}$ & $(<0) \mathbf{0 . 6 1}$ & $\mathbf{- 4}$ & $<0$ & -9 \\
3 & 0.46 & -8 & $(0.32) \mathbf{0 . 5 5}$ & $(-7)-11$ & $(<0) 0.46$ & $\mathbf{- 3}$ & $<0$ & n.a \\
4 & $\mathbf{0 . 6 3}$ & $\mathbf{- 5}$ & $\mathbf{( 0 . 6 3 )} \mathbf{0 . 7 7}$ & $(-6) \mathbf{- 3}$ & $(0.35) \mathbf{0 . 7 6}$ & $\mathbf{- 2}$ & $<0$ & n.a \\
6 & $\mathbf{0 . 5 7}$ & $\mathbf{- 2}$ & $(0.41) \mathbf{0 . 5 6}$ & $(-9) \mathbf{- 1}$ & $(<0)<0$ & $\mathbf{- 2}$ & $<0$ & n.a \\
8 & $\mathbf{0 . 5 6}$ & $\mathbf{- 3}$ & $(0.39) \mathbf{0 . 6 9}$ & $(-7) \mathbf{- 3}$ & $(0.17) \mathbf{0 . 5 9}$ & $\mathbf{- 3}$ & $<0$ & n.a \\
9 & $\mathbf{0 . 6 3}$ & -6 & $\mathbf{( 0 . 5 4 )} \mathbf{0 . 8 0}$ & $(-1) \mathbf{- 2}$ & $(<0) \mathbf{0 . 5 0}$ & $\mathbf{0}$ & $<0$ & n.a \\
12 & $<0$ & 9 & $(<0)<0$ & $(-4) 6$ & $(<0)<0$ & $\mathbf{4}$ & $<0$ & -8 \\
\hline
\end{tabular}

Table 4: Nash-Sutcliffe Efficiency (NSE) index and difference between start of observed and simulated runoff for rainfall events used for calibration and validation. Analysis for event 7 are not shown. Values in bold indicate satisfactory model performance. Parentheses denote GR1. PFE referrers to time between simulated and observed peak flows. Negative values indicate delayed simulated peaks.
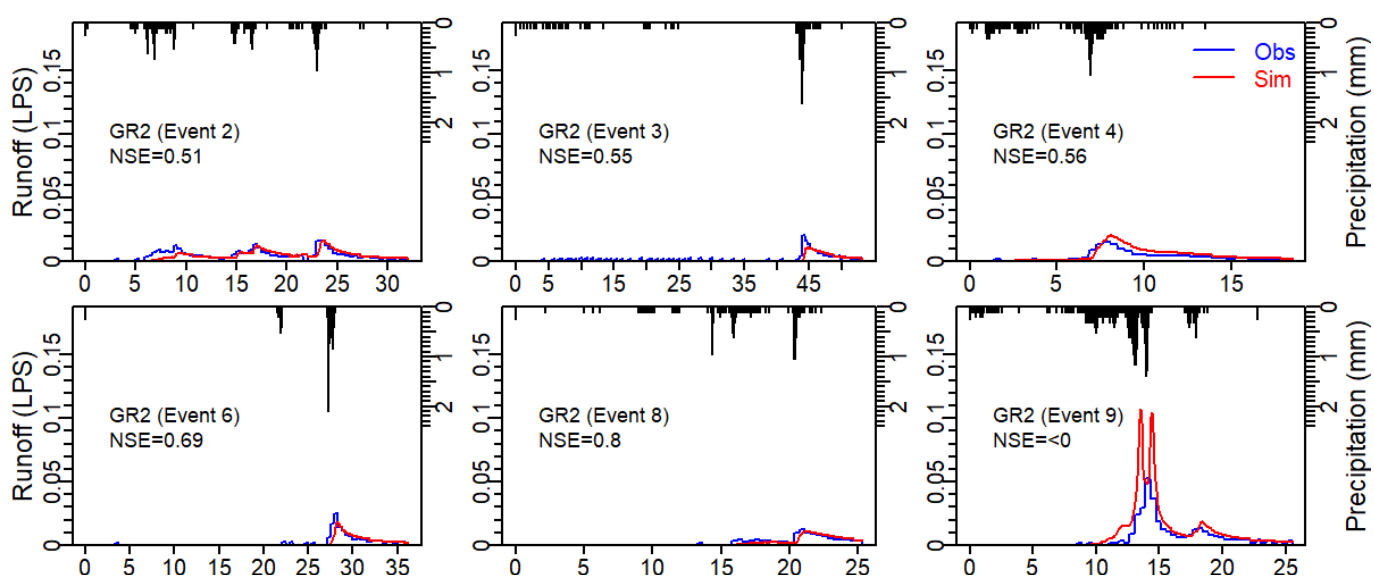

Figure 1: Hyeto-hydrographs of 6 validation events based on parameter sets from calibration event 5. Observed (blue), simulated (red) runoff and corresponding NSE values are shown.

\section{Discussion}

\subsection{Accuracy of the LID-GR module}

In this study, we investigated the accuracy of SWMMs LID-GR module. Runoff response from two GRs have been simulated. The results show that runoff can be simulated accurately, but with certain limitations. The drainage mat in the LID-GR module only accounts for transportation and no storage, while laboratory tests conducted primary to this study show that this mat can retain 7-10 mm of water. Even though extra storage was added to the substrate layer, this effect proved limited. as water flow through the substrate is quicker than through the drain mat, due to the high permeability of GR soils. This might explain the model's tendency to overestimate peak flows.

The only difference between the experimental green roofs, GR1 and GR2 in our study is the extra plastic drainage board in GR1. Despite the extra storage supplied by the drainage board, GR1 generates more runoff than GR2. Moreover, it was observed that the cups are hardly filled, even after heavy 
watering of the roof (Braskerud, 2014).This indicates that water flows vertically through the felt and through the holes of the drainage board and then along the roof, optionally along the drainage board's surface. As for today, the LID-GR module is unable to simulate this process. Assumingly, better simulation results would be achieved if the module allowed for storage capacity in the drain mat and flow along smoother surfaces, i.e. along roof surfaces, under plastic drainage boards.

\subsection{LID-GR parameter sensitivity}

Burszta-Adamiak and Mrowiec (2013) and Palla and Gnecco (2015) recognize initial saturation as influential to the model output, but this study shows no sensitivity to the model input. This may be reasoned with (i) uncertainties related to the soil moisture measurements, (ii) the preliminary burn-in simulation period of 1 hour, (iii) available storage is very small compared to precipitation volume in events used in this study, or (iv) the fact that initial saturation does not exclusively refer to the substrate, but also the drainage mat (Peng \& Stovin, 2017).

Conductivity shows large variations, in our study as well as in literature, ranging from $38 \mathrm{~mm} / \mathrm{h}$ (Krebs et al., 2016) to $1000 \mathrm{~mm} / \mathrm{h}$ (Palla \& Gnecco, 2015; Peng \& Stovin, 2017). Here, it does not tend to vary with rainfall characteristics nor initial conditions. However, it needs to be seen in relation to conductivity slope which is more dominant at unsaturated soil moisture levels. Peng and Stovin (2017) and Krebs et al. (2016) recognize conductivity slope as sensitive to peak runoff, which is compatible with this parameter being correlated with peak precipitation intensity found in this study.

The limitations to this study is the size of the experimental site. The distance to the gutter is short, and the GR built-up is thin. This might affect (i) large variations in the optimal parameter sets and (ii) the fact that detention processes seem to take place in either the substrate layer or the drainage mat. Inconsistencies in the parameters related to the drainage mat causing more or less free water flow may explain the model's tendency to delay and overestimate peak flows. Vertical flow in the drainage layer should be made possible, so that the model also can represent GRs with plastic drainage boards.

\section{Conclusion}

In this study, the accuracy of SWMMs LID-GR module has been investigated. Model performance improve after calibration. However, the model generally overestimates and delays peak flows. Caution should be made when using calibrated parameter sets to validation events as they should feature similar characteristics as the events calibrated for, to achieve best model performance. Furthermore, this study has examined parameter sensitivity with respect to rainfall characteristics and initial conditions. Conductivity slope is sensitive to precipitation intensity and is thus important when modelling detention performance. Some refinements should be made to the LID-GR module, such as improvement of the drainage layer to better represent physical features of a GR. 


\section{References}

Bengtsson, L. (2005). Peak flows from thin sedum-moss roof. Hydrology Research, 36(3), 269-280.

Berndtsson, J. C. (2010). Green roof performance towards management of runoff water quantity and quality: A review. Ecological Engineering, 36(4), 351-360. doi:10.1016/j.ecoleng.2009.12.014

Braskerud, B. C. (2014). Green roofs and cloud burst precipitation. Grønne tak og styrtregn. Oslo: NVE $65 / 2014$.

Burszta-Adamiak, E., \& Mrowiec, M. (2013). Modelling of green roofs' hydrologic performance using EPA's SWMM. Water Science and Technology, 68(1), 36-42.

Carson, T., Keeley, M., et al. (2017). Assessing methods for predicting green roof rainfall capture: A comparison between full-scale observations and four hydrologic models. Urban Water Journal, 14(6), 589-603.

Carson, T., Marasco, D., et al. (2013). Hydrological performance of extensive green roofs in New York City: observations and multi-year modeling of three full-scale systems. Environmental Research Letters, 8(2), 024036.

Cipolla, S. S., Maglionico, M., et al. (2016). A long-term hydrological modelling of an extensive green roof by means of SWMM. Ecological Engineering, 95, 876-887. doi:10.1016/j.ecoleng.2016.07.009

Duan, Q. Y., Sorooshian, S., et al. (1992). EFFECTIVE AND EFFICIENT GLOBAL OPTIMIZATION FOR CONCEPTUAL RAINFALL-RUNOFF MODELS. Water resources research, 28(4), 1015-1031. doi:10.1029/91wr02985

Hakimdavar, R., Culligan, P. J., et al. (2014). Scale dynamics of extensive green roofs: Quantifying the effect of drainage area and rainfall characteristics on observed and modeled green roof hydrologic performance. Ecological Engineering, 73, 494-508.

Hilten, R. N., Lawrence, T. M., et al. (2008). Modeling stormwater runoff from green roofs with HYDRUS-1D. Journal of hydrology, 358(3-4), 288-293. doi:10.1016/j.jhydrol.2008.06.010

Johannessen, B. G., Hanslin, H. M., et al. (2017). Green roof performance potential in cold and wet regions. Ecological Engineering, 106, 436-447.

Kasmin, H., Stovin, V. R., et al. (2010). Towards a generic rainfall-runoff model for green roofs. Water Science and Technology, 62(4), 898-905. doi:10.2166/wst.2010.352

Krebs, G., Kuoppamäki, K., et al. (2016). Simulation of green roof test bed runoff. Hydrological processes, 30(2), 250-262.

Locatelli, L., Mark, O., et al. (2014). Modelling of green roof hydrological performance for urban drainage applications. Journal of hydrology, 519, 3237-3248. doi:10.1016/j.jhydrol.2014.10.030

Palla, A., \& Gnecco, I. (2015). Hydrologic modeling of Low Impact Development systems at the urban catchment scale. Journal of hydrology, 528, 361-368.

Peng, Z., \& Stovin, V. (2017). Independent Validation of the SWMM Green Roof Module. Journal of Hydrologic Engineering, 22(9), 04017037.

Rossman, L. A. (2015). Storm Water Management Model User's Manual Version 5.1. U.S. EPA, Cincinnati.

Stovin, V., Vesuviano, G., et al. (2017). Defining green roof detention performance. Urban Water Journal, 14(6), 574-588.

Stovin, V., Vesuviano, G., et al. (2012). The hydrological performance of a green roof test bed under UK climatic conditions. Journal of hydrology, 414, 148-161. doi:10.1016/j.jhydrol.2011.10.022

Villarreal, E. L., \& Bengtsson, L. (2005). Response of a Sedum green-roof to individual rain events. Ecological Engineering, 25(1), 1-7. 
Voyde, E., Fassman, E., et al. (2010). Hydrology of an extensive living roof under sub-tropical climate conditions in Auckland, New Zealand. Journal of hydrology, 394(3-4), 384-395. doi:10.1016/j.jhydrol.2010.09.013 